05,12

\title{
Магнитные свойства допированных висмутом титанатов-пирохлоров иттербия и гольмия
}

\author{
(C) А.Б. Ринкевич ${ }^{1}$, М.С. Королева ${ }^{2}$, И.В. Пийр ${ }^{2}$, Д.В. Перов ${ }^{1}$ \\ ${ }^{1}$ Институт фозики металлов им. М.Н. Михеева УрО РАН, \\ Екатеринбург, Россия \\ ${ }^{2}$ Институт химии Коми НЦ УрО РАН \\ Сыктывкар, Россия \\ E-mail: rin@imp.uran.ru
}

Поступила в Редакцию 25 декабря 2018 г.

В окончательной редакции 16 апреля 2019 г.

Принята к публикации 16 апреля 2019 г.

Синтезированы допированные висмутом титанаты иттербия и гольмия и исследованы их магнитные свойства. Измерены кривые намагничивания и температурные зависимости восприимчивости в полях до $30 \mathrm{kOe}$ при температурах от 2 до $300 \mathrm{~K}$. Проведено сравнение свойств допированных и недопированных титанатов. В температурных зависимостях произведения восприимчивости и температуры есть линейный участок, причем знак наклона этих зависимостей изменяется при допировании для обоих титанатов $\mathrm{Ho}_{2} \mathrm{Ti}_{2} \mathrm{O}_{7}$ и $\mathrm{Yb}_{2} \mathrm{Ti}_{2} \mathrm{O}_{7}$. На основе изучения температурных зависимостей восприимчивости проведен анализ магнитного дипольного и обменного взаимодействия титанатов.

Ключевые слова: редкоземельные титанаты, структура пирохлора, кривая намагничивания, магнитная восприимчивость.

DOI: 10.21883/FTT.2019.08.47969.345

\section{1. Введение}

В последние годы значительный интерес вызывает изучение необычных магнитных свойств редкоземельных титанатов со структурой пирохлора. Состав этих титанатов выражается формулой $R_{2}^{3+} \mathrm{Ti}_{2}^{4+} \mathrm{O}_{7}$, где $R^{3+}$ трехвалентный ион редкоземельного элемента. Некоторые ионы $R^{3+}$ имеют большой магнитный момент, например, ионы гольмия. В кристаллической решетке ионы занимают позиции в вершинах тетраэдров, что допускает существование фрустрированных магнитных моментов. Магнитные свойства титанатов-пирохлоров вызывают интерес в связи с проблемой „спинового льда“ особого магнитного состояния, установленного для титанатов гольмия и диспрозия при низких температурах. Титанаты гольмия и диспрозия обладают свойствами классического, а титанат иттербия рассматривался как кандидат на реализацию состояния квантового спинового льда $[1,2]$. В случае классического спинового льда доминирует дальнодействующее магнитное дипольное взаимодействие. Магнитная восприимчивость монокристаллов титанатов $\mathrm{Dy}_{2} \mathrm{Ti}_{2} \mathrm{O}_{7}$ и $\mathrm{Ho}_{2} \mathrm{Ti}_{2} \mathrm{O}_{7}$ исследована в работе [3]. В титанате $\mathrm{Ho}_{2} \mathrm{Ti}_{2} \mathrm{O}_{7}$ основное состояние ионов гольмия - некрамерсов дублет, существует щель $\sim 300 \mathrm{~K}$ между дублетом основного состояния с единственной отличной от нуля компонентой $g$-тензора $\left(g_{\perp}=0\right)$ и первым возбужденным состоянием. Этот факт является основанием для рассмотрения свойств этого материала при низких температурах как системы, описываемой в модели Изинга [4].
Титанат $\mathrm{Yb}_{2} \mathrm{Ti}_{2} \mathrm{O}_{7}$ ранее рассматривался как возможный материал со свойствами квантовой спиновой жидкости [2]. Однако в последние годы преобладает иное мнение и этот титанат считается ферромагнетиком с неколлинеарным расположением магнитных моментов („splayed ferromagnet“) [5,6]. Теоретическое описание магнитных взаимодействий в $\mathrm{Yb}_{2} \mathrm{Ti}_{2} \mathrm{O}_{7}$ ведется на основе модели „псевдоспин 1/2“ [7]. Температурные зависимости намагниченности монокристаллов в магнитном поле были рассчитаны теоретически и исследованы экспериментально в [7]. Для температур $T>1.8 \mathrm{~K}$ получено хорошее согласие между теорией и экспериментом. Вопрос о существовании дальнего магнитного порядка в $\mathrm{Yb}_{2} \mathrm{Ti}_{2} \mathrm{O}_{7}$ вызвал дискуссию. В работе [7] магнитное упорядочение в $\mathrm{Yb}_{2} \mathrm{Ti}_{2} \mathrm{O}_{7}$ не было обнаружено. Однако в работах $[8,9]$ были найдены аргументы в пользу ферромагнитного упорядочения. Эти представления были скорректированы в $[10,11]$. В [11] ферромагнитное упорядочение в $\mathrm{Yb}_{2} \mathrm{Ti}_{2} \mathrm{O}_{7}$ при низких температурах было вновь подтверждено, причем сделано утверждение, что магнитные моменты ориентированы приблизительно вдоль осей $\langle 100\rangle$, но несколько отклонены от этих направлений.

Бо́льшая часть работ по исследованию низкотемпературных магнитных свойств титанатов редкоземельных элементов со структурой пирохлоров выполнена на моно- и поликристаллах, и лишь немногие исследования - на пленочных или нанокомпозитных образцах. В работе [12] описано получение и исследование пленки из $\mathrm{Ho}_{2} \mathrm{Ti}_{2} \mathrm{O}_{7}$. Наблюдалось плато на кривой намагничи- 
вания при направлении поля вдоль оси [111]. В нанокомпозитных образцах титанатов с частицами $\mathrm{Yb}_{2} \mathrm{Ti}_{2} \mathrm{O}_{7}$, $\mathrm{Dy}_{2} \mathrm{Ti}_{2} \mathrm{O}_{7}$ и $\mathrm{Er}_{2} \mathrm{Ti}_{2} \mathrm{O}_{7}$ размером не более $60 \mathrm{~nm}$ наблюдалась петля гистерезиса, причем спадающие ветви петли в некотором интервале температур пересекались при одном и том же значении магнитного поля [13].

Цель данной работы состоит в исследовании и сопоставлении магнитных свойств допированных висмутом и недопированных титанатов гольмия и иттербия. Титанаты гольмия и иттербия выбраны, поскольку эти титанаты сами по себе имеют необычные магнитные свойства. При этом магнитные взаимодействия в титанате гольмия описываются в модели Изинга, а в титанате иттербия - в так называемой „ $X-Y^{“}$ модели типа „легкая плоскость“ [14]. Выбор висмута как допирующего элемента вызван тем, что ион $\mathrm{Bi}^{3+}$ имеет значительно больший радиус, чем ионы $\mathrm{Ho}^{3+}$ и $\mathrm{Yb}^{3+}$. Поэтому замещение ионов редкоземельного элемента на ион $\mathrm{Bi}^{3+}$ можно рассматривать как создание химического давления. Влияние допирования висмутом на межатомные расстояния в редкоземельном рутенате $\left(\mathrm{Bi}_{2-x} \mathrm{Pr}_{x}\right) \mathrm{Ru}_{2} \mathrm{O}_{7}$ $(0 \leq x \leq 2)$ со структурой пирохлора было исследовано в [15]. Ионные радиусы висмута и празеодима различаются не очень сильно. Было установлено, что при изменении содержания висмута происходит переход металл-полупроводник. При большой концентрации празеодима магнитные свойства определяются локализованным моментом иона $\operatorname{Pr}^{3+}$, причем наблюдаются сильные антиферромагнитные корреляции. Магнитные корреляции в монокристалле $\mathrm{Ho}_{2} \mathrm{Ti}_{2} \mathrm{O}_{7}$, допированном иттрием, исследованы методами рассеяния нейтронов в [16]. Было установлено, что в интервале температур от 2 до $10 \mathrm{~K}$ нейтронные данные согласуются с моделью спинового льда с взаимодействием ближайших ионов гольмия. Ниже $2 \mathrm{~K}$ данные согласуются с моделью дипольного спинового льда. Обнаружены также признаки антиферромагнитных корреляций. Изменения магнитного состояния и энтропии были исследованы путем частичного замещения ионов титана гольмием в системе $\mathrm{Ho}_{2}\left(\mathrm{Ti}_{2-x} \mathrm{Ho}_{x}\right) \mathrm{O}_{7-x / 2}$ [17]. При таком легировании добавляются дополнительные ионы $\mathrm{Ho}^{3+}$ с большим магнитным моментом, изменяющие картину геометрической фрустрации. Однако состояние спинового льда сохраняется даже при высоких степенях допирования. В работе [18] исследованы спектры люминесценции и возбуждения люминесценции поликристаллических образцов титаната иттрия, допированного иттербием, то есть системы $\left(\mathrm{Yb}_{x} \mathrm{Y}_{1-x}\right)_{2} \mathrm{Ti}_{2} \mathrm{O}_{7}$ при температурах от 4.2 до $300 \mathrm{~K}$. Проведен анализ спектров на основе теории кристаллического поля и восстановлена структура уровней иона $\mathrm{Yb}^{3+}$. Влияние замещения ионов титана на олово и германий, рассматриваемое как эффект химического давления, исследовано [19] с использованием данных о восприимчивости в переменных полях. Показано, что химическое давление может существенно воздействовать на квантовые спиновые флуктуации ионов $\mathrm{Yb}^{3+}$.
В нашем случае ионы висмута замещают в допированных составах ионы $\mathrm{Ho}^{3+}$ и $\mathrm{Yb}^{3+}$ в кристаллической решетке, увеличивая параметр решетки и значительно изменяя расстояния между ионами. Следовательно, в допированных титанатах можно ожидать изменения взаимодействия между соседними ионами, обладающими магнитным моментом, по сравнению с недопированными. По сравнению с работой [19], осуществлено не только изменение расстояний между ионами, но и изменена концентрация редкоземельных ионов, обладающих магнитным моментом. Тип кристаллической решетки при допировании не изменяется. В работе выполнены измерения кривых намагничивания и температурных зависимостей восприимчивости в полях до $30 \mathrm{kOe}$ при температурах от 2 до $300 \mathrm{~K}$.

\section{2. Синтез и рентгенографический анализ образцов пирохлоров}

Синтез соединений $\mathrm{Yb}_{2} \mathrm{Ti}_{2} \mathrm{O}_{7}, \quad \mathrm{Ho}_{2} \mathrm{Ti}_{2} \mathrm{O}_{7}$, $\mathrm{Bi}_{1.5} \mathrm{Yb}_{0.5} \mathrm{Ti}_{2} \mathrm{O}_{7} \quad$ и $\quad \mathrm{Bi}_{1.5} \mathrm{Ho}_{0.5} \mathrm{Ti}_{2} \mathrm{O}_{7}$ со структурой типа пирохлора проведен твердофазным методом из исходных оксидов: $\mathrm{Ho}_{2} \mathrm{O}_{3}$ (х. ч.), $\mathrm{Yb}_{2} \mathrm{O}_{3}$ (х. ч.), $\mathrm{Bi}_{2} \mathrm{O}_{3}$ (х. ч.), $\mathrm{TiO}_{2}$ (х. ч., модификация анатаз). Навески оксидов, взятые в стехиометрическом соотношении, тщательно перетирали в яшмовой ступке в течение $30 \mathrm{~min}$. Для ускорения взаимодействия между исходными оксидами порошок прессовали в таблетки с помощью пресс-формы из оргстекла. Полученные таблетки диаметром $d=15 \mathrm{~mm}$ и высотой $h=1.0 \mathrm{~mm}$ помещали в корундовые тигли и подвергали высокотемпературной термообработке в муфельной печи. Режим термообработки образцов представлен в табл. 1. После каждой промежуточной стадии термообработки образцы вновь перетирали и прессовали, что способствует более полному протеканию твердофазной реакции.

Для составов $\mathrm{Bi}_{1.5} \mathrm{Yb}_{0.5} \mathrm{Ti}_{2} \mathrm{O}_{7}$ и $\mathrm{Bi}_{1.5} \mathrm{Ho}_{0.5} \mathrm{Ti}_{2} \mathrm{O}_{7}$ начальная температура прокаливания составляет $650^{\circ} \mathrm{C}$, что необходимо для переведения оксида висмута моноклинной симметрии в более активную модификацию, обладающую флюоритовой структурой. Эта модификация характеризуется разупорядочением кислородных вакансий. Кроме того, предварительное прокаливание образцов предотвращает стадию плавления $\mathrm{Bi}_{2} \mathrm{O}_{3}$ при $824^{\circ} \mathrm{C}$ и, соответственно, его испарение при дальнейшем прокаливании [20].

Таблица 1. Режим термообработки исходной шихты

\begin{tabular}{c|l}
\hline Состав & $T,{ }^{\circ} \mathrm{C}$ (время обработки, час.) \\
\hline $\mathrm{Yb}_{2} \mathrm{Ti}_{2} \mathrm{O}_{7}, \mathrm{Ho}_{2} \mathrm{Ti}_{2} \mathrm{O}_{7}$ & $1200(6), 1200(6), 1200(18)$ \\
\hline $\mathrm{Bi}_{1.5} \mathrm{Yb}_{0.5} \mathrm{Ti}_{2} \mathrm{O}_{7}, \mathrm{Bi}_{1.5} \mathrm{Ho}_{0.5} \mathrm{Ti}_{2} \mathrm{O}_{7}$ & $650(6), 850(6), 950(6)$, \\
& $1000(6), 1050(6)$, \\
& $1100(18), 1115(20)$
\end{tabular}


Таблица 2. Параметры элементарной ячейки и плотность пирохлоров при $25^{\circ} \mathrm{C}$

\begin{tabular}{|c|c|c|c|c|}
\hline Соединение & $a, \AA$ & $\begin{array}{c}\text { Расстояние } \\
(\mathrm{Bi})-\mathrm{R} \text { для позиций } \\
\text { с координационным } \\
\text { числом } 6, \AA\end{array}$ & $\begin{array}{c}\text { Расстояние } \\
R(\mathrm{Bi})-R \text { для позиций } \\
\text { с координационным } \\
\text { числом } 12, \AA\end{array}$ & $\begin{array}{c}\rho \\
\mathrm{g} / \mathrm{cm}^{3}\end{array}$ \\
\hline $\begin{array}{l}\mathrm{Yb}_{2} \mathrm{Ti}_{2} \mathrm{O}_{7} \\
\mathrm{Ho}_{2} \mathrm{Ti}_{2} \mathrm{O}_{7} \\
\mathrm{Bi}_{1.5} \mathrm{Yb}_{0.5} \mathrm{Ti}_{2} \mathrm{O}_{7} \\
\mathrm{Bi}_{1.5} \mathrm{Ho}_{0.5} \mathrm{Ti}_{2} \mathrm{O}_{7}\end{array}$ & $\begin{array}{l}10.025 \\
10.092 \\
10.264 \\
10.279\end{array}$ & $\begin{array}{l}3.5446 \\
3.5701 \\
3.6302 \\
3.6325\end{array}$ & $\begin{array}{l}6.1394 \\
6.1813 \\
6.2877 \\
6.2916\end{array}$ & $\begin{array}{l}7.30 \\
6.95 \\
7.46 \\
7.38\end{array}$ \\
\hline
\end{tabular}

Рентгенофазовый анализ образцов на порошках проведен с использованием дифрактометра SHIMADZU XRD-6000 на $\mathrm{Cu} K_{\alpha}$-излучении с $\lambda=1.54056 \mathrm{~nm}$, в интервале изменения угла $2 \theta$ от $10^{\circ}$ до $80^{\circ}$ (шаг $0.05^{\circ}$ ) и временем экспозиции $2 \mathrm{~s}$. Рентгенограммы образцов, полученные после последнего прокаливания, представлены на рис. 1. Все рефлексы на рентгенограммах составов $\mathrm{Yb}_{2} \mathrm{Ti}_{2} \mathrm{O}_{7}, \mathrm{Ho}_{2} \mathrm{Ti}_{2} \mathrm{O}_{7}, \mathrm{Bi}_{1.5} \mathrm{Yb}_{0.5} \mathrm{Ti}_{2} \mathrm{O}_{7}, \mathrm{Bi}_{1.5} \mathrm{Ho}_{0.5} \mathrm{Ti}_{2} \mathrm{O}_{7}$ описываются пространственной группой $F d \overline{3} m$, что является подтверждением формирования фазы пирохлора. Фаза пирохлора наблюдается в твердых растворах с доминирующей концентрацией висмута $\mathrm{Bi}_{1.5} \mathrm{Yb}_{0.5} \mathrm{Ti}_{2} \mathrm{O}_{7}$, $\mathrm{Bi}_{1.5} \mathrm{Ho}_{0.5} \mathrm{Ti}_{2} \mathrm{O}_{7}$, что заранее не является очевидным, поскольку титанат висмута имеет моноклинную структуру. Рассчитанные по рентгенограммам параметры элементарных ячеек $a$ и плотность $\rho$ представлены в табл. 2 . Из данных табл. 2 видно, что параметр решетки при допировании висмутом увеличивается на $1.78 \%$ для $\mathrm{Ho}_{2} \mathrm{Ti}_{2} \mathrm{O}_{7}$ и на $2.41 \%$ для $\mathrm{Yb}_{2} \mathrm{Ti}_{2} \mathrm{O}_{7}$. Из табл. 2 также видно, что расстояния между ионами редкоземельных элементов $R$ и/или замещающими ионами висмута увеличились при допировании на 1.75 и $1.78 \%$ для связей $\mathrm{Ho}-\mathrm{Ho}$ и $\mathrm{Bi}(\mathrm{Ho})-\mathrm{Bi}(\mathrm{Ho})$ и на $2.41 \%$ для связей $\mathrm{Yb}-\mathrm{Yb}$ и $\mathrm{Bi}(\mathrm{Yb})-\mathrm{Bi}(\mathrm{Yb})$. Рентгеноструктурные данные

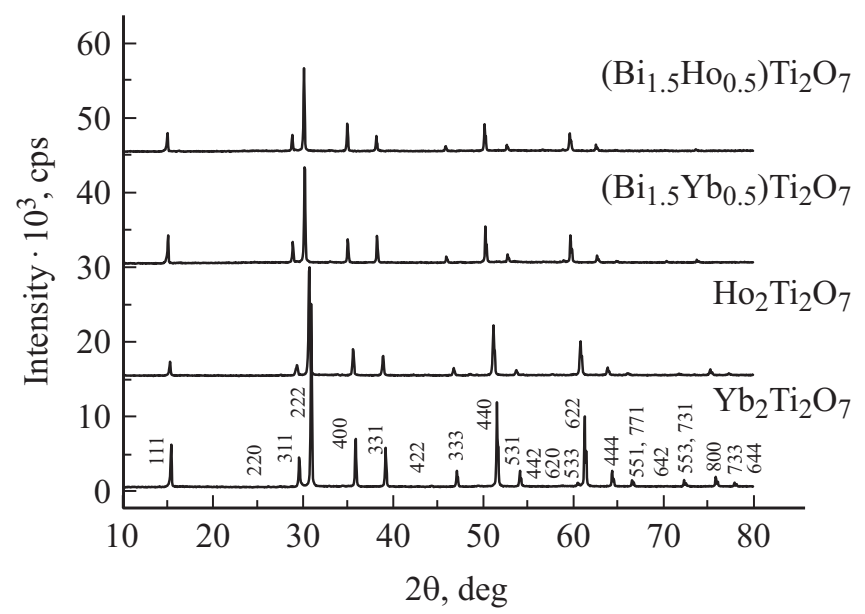

Рис. 1. Рентгенограммы соединений $\mathrm{Yb}_{2} \mathrm{Ti}_{2} \mathrm{O}_{7}, \mathrm{Ho}_{2} \mathrm{Ti}_{2} \mathrm{O}_{7}$, $\mathrm{Bi}_{1.5} \mathrm{Yb}_{0.5} \mathrm{Ti}_{2} \mathrm{O}_{7}$ и $\mathrm{Bi}_{1.5} \mathrm{Ho}_{0.5} \mathrm{Ti}_{2} \mathrm{O}_{7}$ со структурой пирохлора, полученные на порошках при $25^{\circ} \mathrm{C}$. для недопированных титанатов близки к опубликованным ранее $[21,22]$.

\section{3. Кривые намагничивания}

Магнитные свойства системы $\left(\mathrm{Bi}_{2-x} \mathrm{Pr}_{x}\right) \mathrm{Ru}_{2} \mathrm{O}_{7}$ $(0 \leq x \leq 2)$, имеющей структуру пирохлора, ранее были изучены в [15]. В этой системе радиусы ионов $\mathrm{Bi}$ и $\mathrm{Pr}$ отличаются не очень сильно. Было показано, что при увеличении содержания празеодима парамагнетизм Паули металла $\mathrm{Bi}_{2} \mathrm{Ru}_{2} \mathrm{O}_{7}$ заменяется парамагнитной фазой магнитных моментов $4 d$ и $4 f$ электронов, локализованных на ионах рутения и празеодима соответственно. Ионы $\operatorname{Pr}^{3+}$ в твердых растворах распределяются случайным образом по подрешетке $\mathrm{R}_{4} \mathrm{O}$ и занимают позиции в узлах тетраэдров решетки пирохлора. При содержании празеодима $x \geq 0.6$ присутствуют антиферромагнитные корреляции, свидетельствующие о сильных антиферромагнитных взаимодействиях. Радиусы ионов $\mathrm{Ho}^{3+}(0.89 \AA)$ и $\mathrm{Yb}^{3+}(0.86 \AA)$ значительно отличаются от радиуса иона висмута $(1.17 \AA)$. Поэтому при допировании висмутом титанатов гольмия и иттербия изменяются расстояния между редкоземельными ионами, обладающими существенно большим магнитными моментами, чем ионы празеодима, и можно ожидать существенных изменений магнитных свойств этих допированных висмутом титанатов.

Магнитные измерения выполнены на установке MPMS-5XL в интервале температур от 2 до $300 \mathrm{~K}$ и в магнитных полях до $30 \mathrm{kOe}$. Были измерены кривые намагничивания при нескольких температурах и температурная зависимость магнитной восприимчивости. В этом разделе мы рассмотрим кривые намагничивания образцов. При наименьшей температуре $T=2 \mathrm{~K}$ кривые намагничивания как допированных висмутом образцов, так и не допированных, проявляют признаки насыщения, см. рис. 2. Однако в полях до $30 \mathrm{kOе}$ полного насыщения не достигается. Зависимости, измеренные при более высокой температуре $T=10 \mathrm{~K}$ в полях до $30 \mathrm{kOe}$, выглядят как линейные функции. Наши результаты по измерению кривых намагничивания недопированных титанатов можно сравнить с имеющимися в литературе данными. По оси ординат на рис. $3, a, b$ отложен эффективный магнитный момент в расчете на редкоземельный ион. 

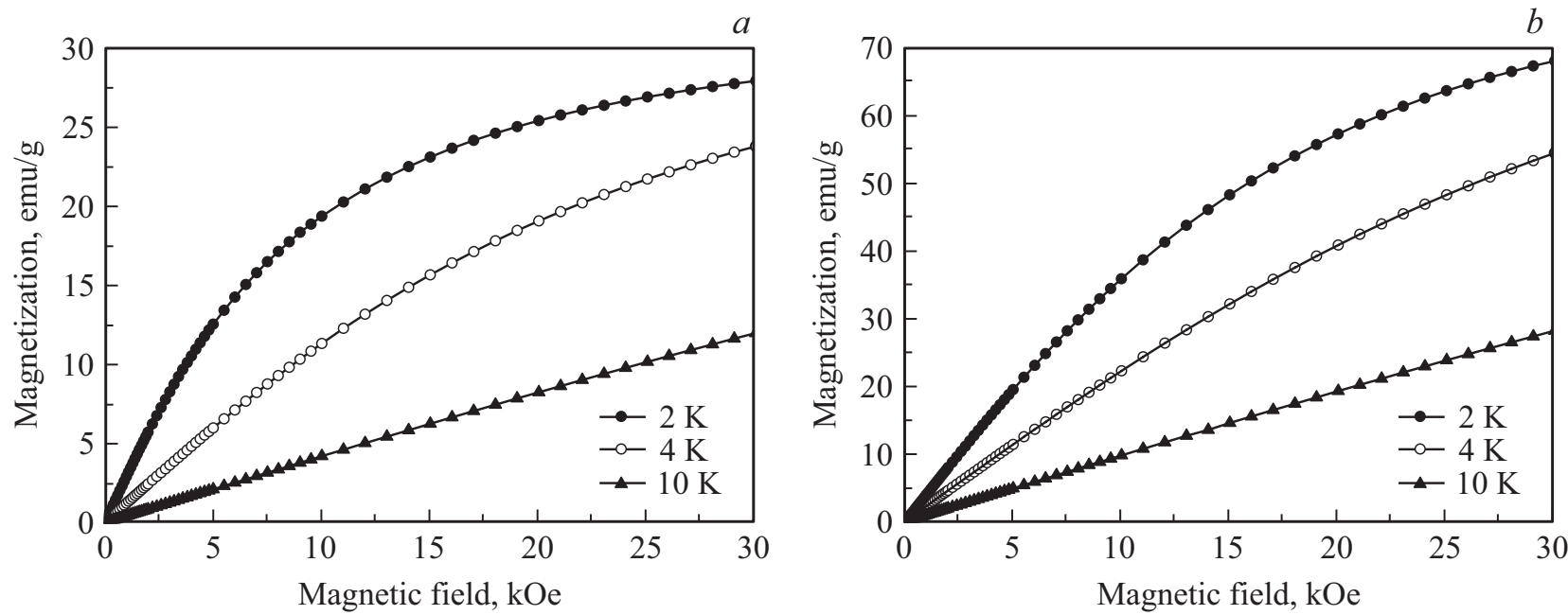

Рис. 2. Кривые намагничивания образцов $\mathrm{Yb}_{2} \mathrm{Ti}_{2} \mathrm{O}_{7}(a)$ и $\mathrm{Bi}_{1.5} \mathrm{Yb}_{0.5} \mathrm{Ti}_{2} \mathrm{O}_{7}(b)$, измеренные при разных температурах.
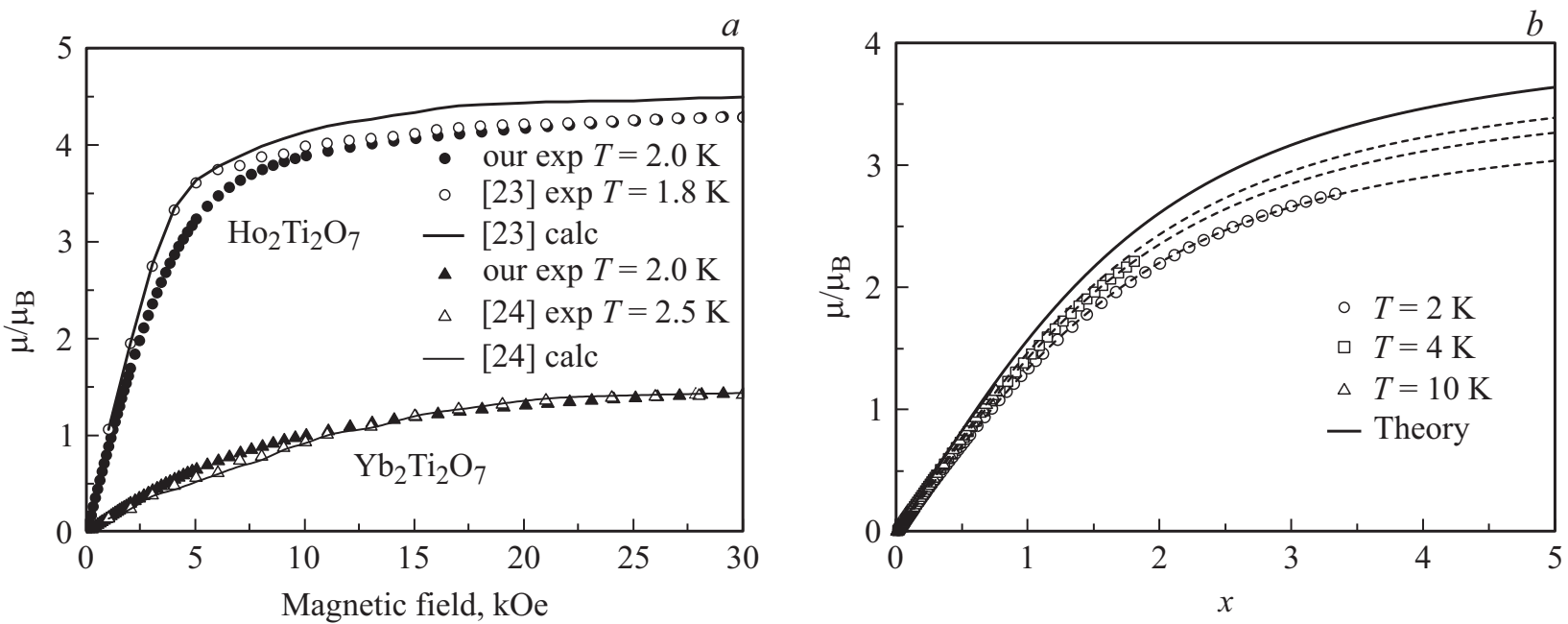

Рис. 3. Сопоставление кривых намагничивания для титанатов $\mathrm{Yb}_{2} \mathrm{Ti}_{2} \mathrm{O}_{7}, \mathrm{Ho}_{2} \mathrm{Ti}_{2} \mathrm{O}_{7}$ с результатами расчетов и измерений из $[23,24](a)$; аппроксимация кривых намагничивания функциями Бриллюэна для состава $\mathrm{Bi}_{1.5} \mathrm{Yb}_{0.5} \mathrm{Ti}_{2} \mathrm{O}_{7}(b)$. Результаты измерений показаны символами, результаты расчетов - сплошными линиями.

На рис. 3, a, помимо наших экспериментальных данных, приведены еще экспериментальные и рассчитанные теоретически кривые намагничивания для $\mathrm{Ho}_{2} \mathrm{Ti}_{2} \mathrm{O}_{7}$ из [23] и для $\mathrm{Yb}_{2} \mathrm{Ti}_{2} \mathrm{O}_{7}$ из [24]. Расчеты для $\mathrm{Ho}_{2} \mathrm{Ti}_{2} \mathrm{O}_{7}$ в [23] были выполнены в модели „спин $1 / 2$ “ путем усреднения по ориентациям поля для порошкового образца, принимая значение эффективного $g$-фактора равным 18.7. В [24] в расчетах, выполненных для $\mathrm{Yb}_{2} \mathrm{Ti}_{2} \mathrm{O}_{7}$, также выполнено усреднение по ориентациям поля, и принято значение $g=3.46$. Наши экспериментальные результаты для $\mathrm{Yb}_{2} \mathrm{Ti}_{2} \mathrm{O}_{7}$ близки к рассчитанным и измеренным в [24], для $\mathrm{Ho}_{2} \mathrm{Ti}_{2} \mathrm{O}_{7}$, в области перехода кривой намагничивания к насыщению существует отличие от [23], связанное, вероятно, с тем, что наши измерения выполнены при несколько более высокой температуре.

В [23] констатируется, что низкотемпературное намагничивание титанатов не может быть правильно описано функцией Бриллюэна из-за влияния одноионной анизотропии. Тем не менее, мы приведем пример аппроксимации кривой намагничивания функцией Бриллюэна для состава $\mathrm{Bi}_{1.5} \mathrm{Yb}_{0.5} \mathrm{Ti}_{2} \mathrm{O}_{7}$ с тем, чтобы выяснить, сколь велики отличия от модели свободного иона для допированных титанатов. Результаты аппроксимации показаны на рис. $3, b$. По оси абсцисс отложена величина $x=\mu_{e f f} H / k_{B} T$, где $\mu_{e f f}=g \sqrt{J(J+1)}, \mu_{e f f}-$ эффективный магнитный момент редкоземельного иона, $H-$ внешнее постоянное магнитное поле, $k_{B}-$ постоянная Больцмана, $g=8 / 7-$ фактор Ланде мультиплета ${ }^{2} \mathrm{~F}_{7 / 2}, k_{B}-$ постоянная Больцмана. На этом рисунке показана также зависимость, рассчитанная по формуле Бриллюэна для квантового числа $J=7 / 2$ и магнитного момента $\mu=4.54 \mu_{B}$, где $\mu_{B}-$ магнетон Бора. Расчеты магнитного момента на ион гольмия выполнены по 
формуле [25]:

$$
\mu=g \mu_{B} J B_{J}(y)
$$

где

$$
B_{J}(y)=\frac{2 J+1}{2 J} \operatorname{cth}\left(\frac{2 J+1}{2 J} y\right)-\frac{1}{2 J} \operatorname{cth}\left(\frac{y}{2 J}\right),
$$

где $y=\frac{g \mu_{B} J H}{k_{B} T}, g-$ фактор Ланде, $N-$ число магнитных ионов в $\mathrm{cm}^{3}$. Эффективный магнитный момент на один редкоземельный ион рассчитывается следующим образом

$$
\mu_{e f f}=g \sqrt{J(J+1)} .
$$

Из рис. $3, b$ видно, что измеренные зависимости в целом достаточно близки к рассчитанной зависимости для иона $\mathrm{Yb}^{3+}$, поэтому можно полагать, что магнитные свойства $\mathrm{Bi}_{1.5} \mathrm{Yb}_{0.5} \mathrm{Ti}_{2} \mathrm{O}_{7}$ в значительной степени определяются локализованным магнитным моментом иттербия. Все же можно отметить, что по мере понижения температуры экспериментальные зависимости все более отличаются от расчетной.

\section{4. Температурная зависимость магнитной восприимчивости}

В этом разделе будут приведены результаты измерений температурной зависимости восприимчивости, которые имеют важное значение для определения типа взаимодействий в исследуемых титанатах. Температурные зависимости обратной начальной дифференциальной восприимчивости, измеренные для составов $\mathrm{Ho}_{2} \mathrm{Ti}_{2} \mathrm{O}_{7}$ и $\mathrm{Bi}_{1.5} \mathrm{Ho}_{0.5} \mathrm{Ti}_{2} \mathrm{O}_{7}$, показаны на рис. 4. По оси ординат отложены безразмерные обратные начальные дифференциальные восприимчивости, нормализованные на значение этой величины для данного состава при $T=2 \mathrm{~K}$. Обе эти зависимости близки к линейным. На рис. 5, $a$ показаны температурные зависимости для

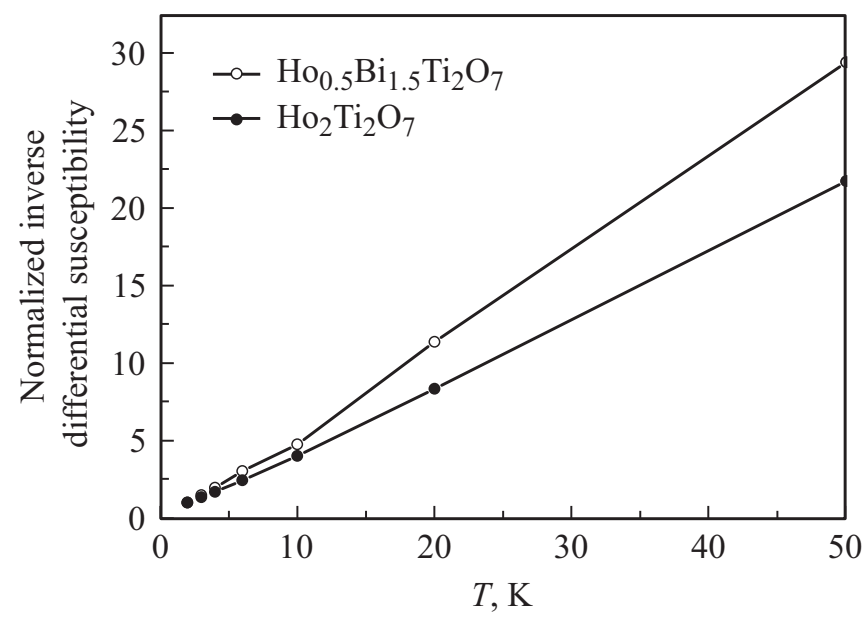

Рис. 4. Температурная зависимость обратной начальной восприимчивости титанатов $\mathrm{Ho}_{2} \mathrm{Ti}_{2} \mathrm{O}_{7}$ и $\mathrm{Bi}_{1.5} \mathrm{Ho}_{0.5} \mathrm{Ti}_{2} \mathrm{O}_{7}$. допированного титаната $\mathrm{Yb}_{0.5} \mathrm{Bi}_{1.5} \mathrm{Ti}_{2} \mathrm{O}_{7}$, измеренные как при нагреве, так и при остывании, в магнитном поле равном $0.1 \mathrm{kOe}$. Эти зависимости практически совпадают, то есть температурный гистерезис восприимчивости отсутствует. Температурная зависимость восприимчивости титаната $\mathrm{Ho}_{2} \mathrm{Ti}_{2} \mathrm{O}_{7}$ измерялась в магнитных полях 0.1 и $0.3 \mathrm{kOe}$. Результат измерения показан на рис. $5, b$. На этом же рисунке сплошной линией показана зависимость, рассчитанная по закону КюриВейсса. Рассчитанная зависимость близка к зависимости, измеренной в поле $0.3 \mathrm{kOe}$, а экспериментально измеренная при $0.1 \mathrm{kOe}$ зависимость при температурах выше $\sim 100 \mathrm{~K}$ несколько отличается. На рис. 5 , с показаны температурные зависимости для четырех титанатов, измеренные в поле $0.3 \mathrm{kOe}$. Отличие зависимостей для $\mathrm{Yb}_{0.5} \mathrm{Bi}_{1.5} \mathrm{Ti}_{2} \mathrm{O}_{7}$ и $\mathrm{Yb}_{2} \mathrm{Ti}_{2} \mathrm{O}_{7}$ от линейных очевидно, во всяком случае, при температурах до $300 \mathrm{~K}$. Для недопированного титаната $\mathrm{Yb}_{2} \mathrm{Ti}_{2} \mathrm{O}_{7}$ этот результат отличается от приведенного в [24], где в интервале температур от 2.5 до $10 \mathrm{~K}$ продемонстрирована линейность температурной зависимости обратной восприимчивости. Отличие от линейности в наших измерениях вызвано рассмотрением значительно более широкого температурного интервала.

Расчет температурной зависимости восприимчивости для титаната гольмия $\mathrm{Ho}_{2} \mathrm{Ti}_{2} \mathrm{O}_{7}$ был выполнен в работе [26] в модели Изинга, исходя из расчета магнитного момента системы спинов, расположенных в вершинах тетраэдра кристаллической подрешетки $\mathrm{R}_{4} \mathrm{O}^{6}$ структуры пирохлора. После выполнения суммирования по всем вершинам выбранного тетраэдра было получено следующее выражение для магнитной восприимчивости титаната гольмия, зависящей от температуры

$$
\chi(T)=\frac{N\left(g \mu_{B}\right)^{2}}{k_{B} T} \frac{S^{2}}{3}\left[1-\frac{3 S^{2}}{2 k_{B} T}\left(2.18 J_{D}+2.67 J_{S}\right)\right] .
$$

В формуле (3) $S=2-$ спин иона $\mathrm{Ho}^{3+}$ в основном состоянии ${ }^{5} \mathrm{I}_{8}$. Было учтено дипольное взаимодействие ближайших соседей с константой $J_{D}$ и суперобменное взаимодействие с константой $J_{S}$. Расчеты в [26] могут считаться приближенными, так как не учитывают наличия орбитального магнитного момента и действия кристаллического поля. Более точный расчет для $\mathrm{Ho}_{2} \mathrm{Ti}_{2} \mathrm{O}_{7}$ и нескольких других титанатов проведен в работе [27]. $\mathrm{B}$ [27] с учетом обменного взаимодействия для ближайших редкоземельных ионов, получено выражение для восприимчивости,

$$
\chi(T)=\frac{N_{A}}{3}\left(\chi_{\|}+2 \chi_{\perp}\right),
$$

где $N_{A}$ - число Авогадро, $\chi_{\|}$и $\chi_{\perp}-$ продольная и поперечная восприимчивости редкоземельного иона относительно локальной оси симметрии третьего порядка. В случае высоких температур, когда $k_{B} T$ превышает расщепление кристаллического поля мультиплета редкоземельного иона, выражение (4) может быть записано 

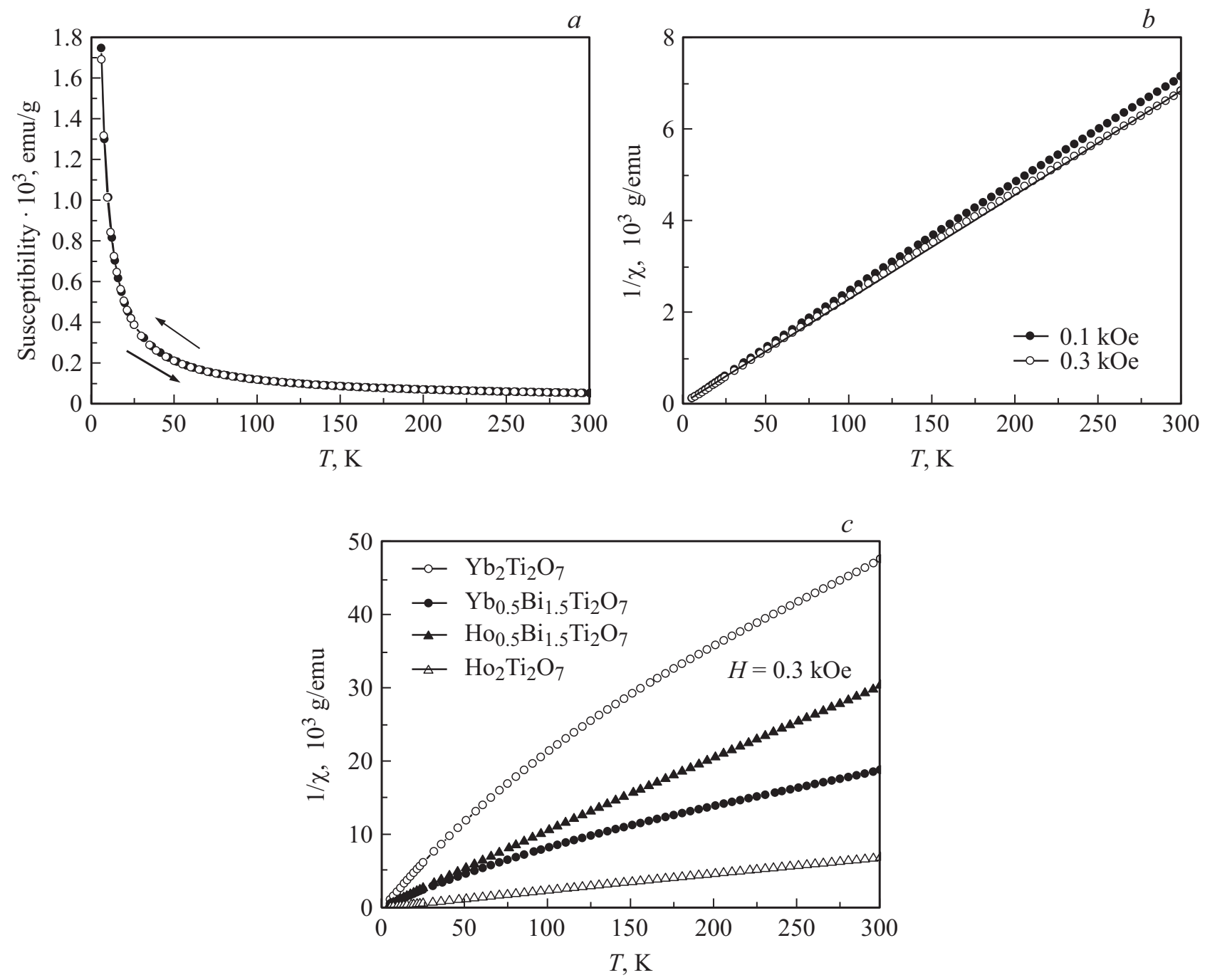

Рис. 5. Температурная зависимость восприимчивости $\mathrm{Yb}_{0.5} \mathrm{Bi}_{1.5} \mathrm{Ti}_{2} \mathrm{O}_{7}$, измеренная в поле $H=0.1 \mathrm{kOe}(a)$; температурная зависимость обратной восприимчивости $\mathrm{Ho}_{2} \mathrm{Ti}_{2} \mathrm{O}_{7}$, измеренная в полях $H=0.1$ и $0.3 \mathrm{kOe}$ и аппроксимация по закону Кюри $(b)$; температурная зависимость обратной восприимчивости титанатов, измеренная в поле $H=0.3 \mathrm{kOe}(c)$.

в виде

$$
\chi(T) \cong N_{A} \frac{C}{T} \frac{\left[1+\left(C_{1}+1.383 \frac{16 \pi}{3 a^{3}}\right) \frac{C}{T}\right]}{1-\left[C_{2}-\frac{64 \pi}{3 a^{3}}\left(1.346-N_{d}\right)\right] \frac{C}{T}},
$$

где $C=\mu_{e f f}^{2} / 3 k_{B}$ - константа в законе Кюри-Вейсса, $a$ - постоянная решетки, $N_{d}$ - размагничивающий фактор, величины $C_{1}$ и $C_{2}$ не зависят от температуры и выражаются через константы, связывающие компоненты магнитного момента вдоль и перпендикулярно направлению связи. Выражение (5) с точностью до членов $O\left(1 / T^{2}\right)$ сводится к закону Кюри-Вейсса, который должен выполняться при высоких температурах. Отклонение от линейности температурной зависимости обратной восприимчивости, предписываемое формулой (5), реализовалось в наших результатах для $\mathrm{Yb}_{0.5} \mathrm{Bi}_{1.5} \mathrm{Ti}_{2} \mathrm{O}_{7}$ и $\mathrm{Yb}_{2} \mathrm{Ti}_{2} \mathrm{O}_{7}$.
Вычисленная в [27] температурная зависимость восприимчивости $\mathrm{Ho}_{2} \mathrm{Ti}_{2} \mathrm{O}_{7}$ хорошо согласуется с экспериментальными данными. Однако для качественного анализа взаимодействий в $\mathrm{Ho}_{2} \mathrm{Ti}_{2} \mathrm{O}_{7}$ удобнее воспользоваться формулой (3), несмотря существенные приближения, использованные при ее выводе. Магнитное дипольное взаимодействие с положительной константой $J_{D}$ способствует параллельному упорядочению спинов, а суперобменное с отрицательной константой $J_{S}$ вызывает фрустрацию. Оценки, выполненные в [26], показали, что влияние второго слагаемого в квадратных скобках в (3) очень существенно сказывается при температурах $\sim 1 \mathrm{~K}$ и ниже. Из (3) следует линейная зависимость произведения $\chi \cdot T$ от $1 / T$. При достаточно высоких температурах линейная зависимость произведения следует и из (5).

Зависимость произведения $\chi \cdot T$ от обратной температуры $1 / T$ для исследованных титанатов показана на рис. 6. Эти измерения выполнены в интервале темпе- 


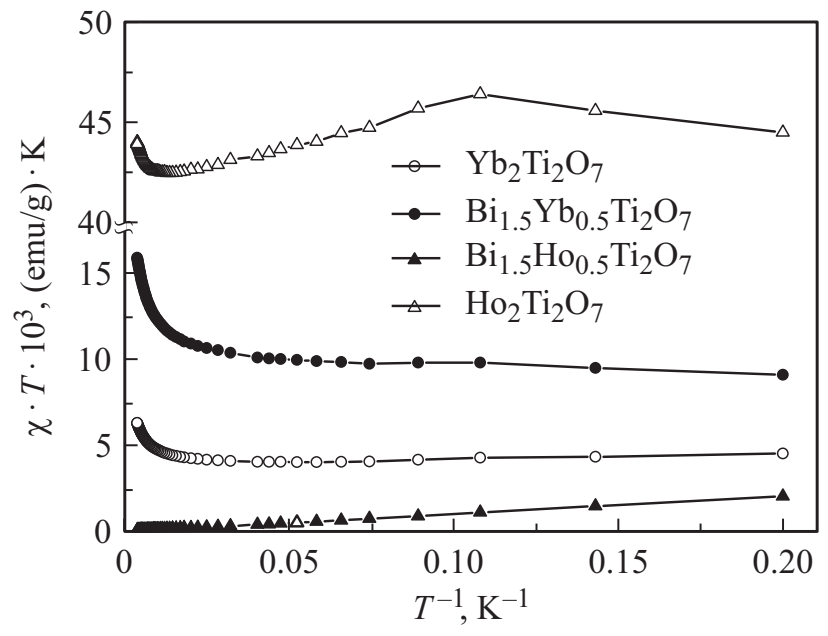

Рис. 6. Зависимость произведения $\chi \cdot T$ от обратной температуры для образцов титанатов-пирохлоров.

ратур от 5 до $300 \mathrm{~K}$. В области низких температур от 5 до $20 \mathrm{~K}$ для составов $\mathrm{Yb}_{2} \mathrm{Ti}_{2} \mathrm{O}_{7}, \mathrm{Bi}_{1.5} \mathrm{Yb}_{0.5} \mathrm{Ti}_{2} \mathrm{O}_{7}$, $\mathrm{Bi}_{1.5} \mathrm{Ho}_{0.5} \mathrm{Ti}_{2} \mathrm{O}_{7}$ действительно присутствует участок $\mathrm{c}$ приблизительно линейной зависимостью. Для титаната гольмия $\mathrm{Ho}_{2} \mathrm{Ti}_{2} \mathrm{O}_{7}$ участок линейности меньше, до $8 \mathrm{~K}$. Отклонение от линейности при более высоких температурах в [26] связывают с нарушением применимости модели Изинга. На участке от 5 до $8 \mathrm{~K}$ наклон зависимости для $\mathrm{Ho}_{2} \mathrm{Ti}_{2} \mathrm{O}_{7}$ на рис. 6 отрицательный. Это говорит о доминировании магнитного дипольного взаимодействия. Для $\mathrm{Yb}_{2} \mathrm{Ti}_{2} \mathrm{O}_{7}$, наоборот, наклон положительный. Вероятно, это связано с тем, что доминирует суперобмен. Отметим, что допирование висмутом меняет знак наклона зависимостей как для $\mathrm{Bi}_{1.5} \mathrm{Yb}_{0.5} \mathrm{Ti}_{2} \mathrm{O}_{7}$ по сравнению с $\mathrm{Yb}_{2} \mathrm{Ti}_{2} \mathrm{O}_{7}$, так и для $\mathrm{Bi}_{1.5} \mathrm{Ho}_{0.5} \mathrm{Ti}_{2} \mathrm{O}_{7}$ по сравнению с $\mathrm{Ho}_{2} \mathrm{Ti}_{2} \mathrm{O}_{7}$.

\section{5. Заключение}

Синтезированы допированные висмутом и недопированные титанаты гольмия и иттербия со структурой пирохлора. Исследованы их низкотемпературные магнитные свойства. Кривые намагничивания недопированных титанатов, измеренные при температуре $2 \mathrm{~K}$, близки к результатам, приведенным в литературе. Установлено, что в температурном интервале от 2 до $10 \mathrm{~K}$ кривые намагничивания допированного титаната $\mathrm{Bi}_{1.5} \mathrm{Yb}_{0.5} \mathrm{Ti}_{2} \mathrm{O}_{7}$ удовлетворительно аппроксимируются функциями Бриллюэна, с отклонениями, увеличивающимися при понижении температуры. Температурные зависимости магнитной восприимчивости не имеют гистерезиса. Для допированного $\mathrm{Bi}_{1.5} \mathrm{Ho}_{0.5} \mathrm{Ti}_{2} \mathrm{O}_{7}$ и недопированного $\mathrm{Ho}_{2} \mathrm{Ti}_{2} \mathrm{O}_{7}$ титанатов гольмия в интервале температур от 2 до $300 \mathrm{~K}$ приблизительно выполняется закон Кюри-Вейсса, а для титанатов иттербия $\mathrm{Bi}_{1.5} \mathrm{Yb}_{0.5} \mathrm{Ti}_{2} \mathrm{O}_{7}$ и $\mathrm{Yb}_{2} \mathrm{Ti}_{2} \mathrm{O}_{7}$ есть значительные отклонения от этого закона.
В температурных зависимостях произведения восприимчивости $\chi$ и температуры $T$ есть линейный участок. Установлено, что знак наклона этих линейных зависимостей изменяется при допировании для обоих титанатов $\mathrm{Ho}_{2} \mathrm{Ti}_{2} \mathrm{O}_{7}$ и $\mathrm{Yb}_{2} \mathrm{Ti}_{2} \mathrm{O}_{7}$. Температурная зависимость восприимчивости титаната гольмия согласуется с предсказаниями теории, учитывающей магнитное дипольное и суперобменное взаимодействия в модели Изинга. При температурах выше $8-10 \mathrm{~K}$ условия применимости модели Изинга нарушаются, и температурная зависимость произведения $\chi \cdot T$ изменяет наклон.

\section{Благодарности}

Авторы благодарны А.В. Королеву за полезные обсуждения.

\section{Финансирование работы}

Работа выполнена при поддержке гранта РФФИ № 1702-00029. Раздел 1 выполнен при поддержке РФФИ, грант № 19-0300642. Результаты раздела 2 получены в соответствии с темой „Функция“. Магнитные измерения выполнены в Центре коллективного пользования при ИФМ УрО РАН.

\section{Список литературы}

[1] L. Bovo, J.A. Bloxsom, D. Prabhakaran, G. Aeppli, S.T. Bramwell. Nature Commun. 4, 1535 (2013).

[2] M.J.P. Gingras, P.A. McClarty. Rep. Prog. Phys. 77, 056501 (2014).

[3] L. Bovo, L.D.C. Jaubert, P.C.W. Holdsworth, S.T. Bramwell. J. Phys.: Condens. Matter. 25, 386002 (2013).

[4] M.J.P. Gingras. In: Introduction to frustrated magnetism / Ed. C. Lacroix. Springer, N. Y. (2011). P. 293.

[5] J.G. Rau, M.J. Gingras. arXiv cond-mat 1806.09638, 25 June 2018.

[6] A. Yaouanc, P. Dalmas de Réotier, L. Keller, B. Roessli, A. Forget. J. Phys.: Condens. Matter 28, 426002 (2016).

[7] N.R. Hayre, K.A. Ross, R. Applegate, T. Lin, R.R.P. Singh, B.D. Gaulin, M.J.P. Gingras. Phys. Rev. B 87, 184423 (2013).

[8] J.A. Hodges, P. Bonville, A. Forget, A. Yaouanc, P. Dalmas de Réotier, G. André, M. Rams, K. Królas, C. Ritter, P.C.M. Gubbens, C.T. Kaiser, P.J.C. King, C. Baines. Phys. Rev. Lett. 88, 077204 (2002).

[9] Y. Yasui, M. Soda, S. Iikubo, M. Ito, M. Sato, N. Hamaguchi, T. Matsushita, N. Wada, T. Takeuchi, N. Aso, K. Kakurai. J. Phys. Soc. Jpn 72, 3014 (2003).

[10] J.S. Gardner, G. Ehlers, N. Rosov, R.W. Erwin, C. Petrovic. Phys. Rev. B 70, 180404 (2004).

[11] L.-J. Chang, S. Onoda, Y. Su, Y.-J. Kao, K.-D. Tsuei, Y. Yasui, K. Kakurai, M.R. Lees. Nature Commun. 3, 992 (2012).

[12] D.P. Leusink, F. Coneri, M. Hoek, S. Turner, H. Idrissi, G. Van Tendeloo, H. Hilgenkamp. APL Materials 2, 032101 (2014).

[13] A.B. Rinkevich, A.V. Korolev, M.I. Samoilovich, S.O. Demokritov, D.V. Perov. J. Magn. Magn. Mater. 453, 137 (2018).

[14] B. Javanparast, A.G.R. Day, Z. Hao, M.J.P. Gingras. Phys. Rev. B 91, 174424 (2015). 
[15] S. Zouari, R. Ballou, A. Cheikhrouhou, P. Strobel. J. Alloys Comp. 476, 43 (2009).

[16] L.J. Chang, Y. Su, Y.-J. Kao, Y.Z. Chou, R. Mittal, H. Schneider, Th. Brückel, G. Balakrishan, M.R. Lees. Phys. Rev. B 82, 172403 (2010).

[17] G.C. Lau, R.S. Freitas, B.G. Ueland, B.D. Muegge, E.L. Duncan, P. Schiffer, R.J. Cava. Nature Phys. 2, 249 (2006).

[18] С.А. Климин, М.Н. Попова, Е.П. Чукалина, Б.З. Малкин, A.P. Закиров, Е. Antic-Fidancev, Ph. Goldner, P. Aschehoug, G. Dhalenne. ФTT 47, 1376 (2005).

[19] Z.L. Dun, M. Lee, E.S. Choi, A.M. Hallas, C.R. Wiebe, J.S. Gardner, E. Arrighi, R.S. Freitas, A.M. Arevalo-Lopez, J.P. Attfield, H.D. Zhou, J.G. Cheng. Phys. Rev. 89, 064401 (2014).

[20] T.A. Vanderah, I. Levin, M.W. Lufaso. Eur. J. Inorg. Chem. 15, 2895 (2005).

[21] L.M. Ershova, B.V. Ignat'ev, L.P. Kusalova, E.E. Lomonova, V.I. Myzina, V.M. Tatarintsev, L.G. Shcherbakova. Inorgan. Mater. 13, 1634 (1977).

[22] N.I. Timofeeva, S.E. Salibekov, I.V. Romanovich. Inorgan. Mater. 7, 785 (1971).

[23] S.T. Bramwell, M.N. Field, M.J. Harris, I.P. Parkin. J. Phys.: Condens. Matter 12, 483 (2000).

[24] J.A. Hodges, P. Bonville, A. Forget, M. Rams, K. Królas, G. Dhalenne. J. Phys.: Condens. Matter 13, 9301 (2001).

[25] Дж. Смарт. Эффективное поле в теории магнетизма. Мир, M. (1968). $271 \mathrm{c}$

[26] R. Siddharthan, B.S. Shastry, A.P. Ramirez, A. Hayashi, R.J. Cava, S. Rosenkranz. Phys. Rev. Lett. 83, 1854 (1999).

[27] B.Z. Malkin, T.T.A. Lummen, P.H.M. van Loosdrecht, G. Dhalenne, A.R. Zakirov. J. Phys.: Condens. Matter 22, 276003 (2010)

Редактор Т.Н. Василевская 